\title{
Total Phenolic Content and Antimicrobial Activity of Different Lithuanian Propolis Solutions
}

\author{
Kristina Ramanauskienè, ${ }^{1}$ Asta Marija Inkènienè, ${ }^{1}$ Vilma Petrikaitė, ${ }^{2}$ and Vitalis Briedis ${ }^{1}$ \\ ${ }^{1}$ Department of Clinical Pharmacy, Lithuanian University of Health Sciences, A. Mickevičiaus 9, 44307 Kaunas, Lithuania \\ ${ }^{2}$ Department of Pharmaceutical Chemistry, Lithuanian University of Health Sciences, A. Mickevičiaus 9, 44307 Kaunas, Lithuania \\ Correspondence should be addressed to Kristina Ramanauskienė; kristinaraman@gmail.com
}

Received 21 November 2012; Revised 1 February 2013; Accepted 18 February 2013

Academic Editor: Vassya Bankova

Copyright (c) 2013 Kristina Ramanauskiene et al. This is an open access article distributed under the Creative Commons Attribution License, which permits unrestricted use, distribution, and reproduction in any medium, provided the original work is properly cited.

\begin{abstract}
The manufacture of ethanol-free propolis solutions offers a broader application. A few trials with Lithuanian propolis have been conducted. The aims of the study are to manufacture propolis water and water-free solutions and evaluate the quality and antimicrobial activity of these solutions. The studied solutions containing $2.5 \%, 5 \%$, and $10 \%$ propolis are prepared. As solvents, purified water, $70 \% \mathrm{v} / \mathrm{v}$ ethanol, $96.3 \% \mathrm{v} / \mathrm{v}$ ethanol, propylene glycol, and their systems were used. Determination of total levels of phenolic compounds (FAE $\mathrm{mg} / \mathrm{g}$ ) is based on colour oxidation-reduction reaction using Folin-Ciocalteu reagent under alkaline conditions and performed at $765 \mathrm{~nm}$ wavelength using UV spectrophotometer. The highest content of phenolic compounds was determined in solutions containing $10 \%$ propolis extracts, and the lowest amounts in $2.5 \%$ propolis extracts. The water extracted the lowest amount of phenolic compounds from crude propolis, ethanol extracted the highest amount, and propylene glycol ranked the middle position. It is determined that technological parameters (stirring, temperature) contribute to content of phenolic compounds. During microbiological study, MICs were determined. The studies showed that water extracted propolis solutions and solvents mixture did not inhibit the growth of the studied microorganisms, and propolis solutions in propylene glycol were found to have antimicrobial activity.
\end{abstract}

\section{Introduction}

Propolis as an active substance is attractive due to its antimicrobial and antimycotic properties and as a natural substance whose effect was proven by biological experiments [1-3]. Raw propolis is composed of $50 \%$ resin, containing flavonoids (flavones: chrysin, apigenin, and luteolin; flavanols: rutin, morin, quercetin, myricetin, kaempferol, quercitrin, and galangin; flavanones: naringin, $( \pm)-$ naringenin, and hesperitin; isoflavones: daidzein and genistein), phenolic acids (caffeic, cinnamic, p-coumaric, ferulic, p-hydroxybenzoic, gallic, etc.) and their esters, $30 \%$ wax, $10 \%$ essential oils, $5 \%$ pollen and $5 \%$ terpenoids, steroids, and amino acids and other organic compounds [4]. The composition of propolis depends on the vegetation at the site of collection. Propolis has been used extensively in folk medicine for many years, and there is substantial evidence indicating that propolis has antiseptic, antifungal, antibacterial, antiviral, anti-inflammatory, antioxidant, immunomodulatory, and antitumor properties [5-7]. The antibacterial, antiviral, and antifungal activities are the most popular among the most extensively investigated biological actions of propolis [8-10]. Propolis is one of the most potent natural antibiotics characterized by a very wide spectrum of effects. Its therapeutic application does not induce germ resistance and does not destroy useful microflora [7]. Propolis has a fungicidal effect on a number of species of fungi, including Candida albicans, Aspergillus niger, Botrytis cinerea, Ascosphaera apis, and Plasmopara viticola [11].

Current applications of propolis include over-the-counter preparations for cold syndrome (upper respiratory tract infections, common cold, and flu-like infection) as well as dermatological preparations useful in wound healing, treatment of burns, acne, herpes simplex and genitalis, and neurodermatitis [12]. Propolis can also be used for dental disease prevention and treatment. It is found that propolis has a strong antimicrobial activity against Streptococcus mutans, Streptococcus sobrinus, Streptococcus sanguinis, and Candida 
albicans, which are important for oral pathogens. Most preparations are based on ethanolic extracts of propolis.

The manufacture of ethanol-free propolis solutions offers a broader application in medicine and everyday use. There are many data on chemical composition of propolis solutions in ethanol and antimicrobial activity. However, a few trials with Lithuanian propylene glycol extracted propolis, its water solutions, and appropriate solvent mixtures have been conducted.

The aims of the study are to manufacture propolis water and water-free solutions and evaluate quality as well as antimicrobial activity of these solutions.

\section{Material and Methods}

2.1. Manufacture of Propolis Solutions. The studied solutions containing $2.5 \%, 5 \%$, and $10 \%$ propolis $200 \mathrm{~mL}$ are prepared. As solvents, purified water, $70 \% \mathrm{v} / \mathrm{v}$ ethanol, $96.3 \% \mathrm{v} / \mathrm{v}$ ethanol, propylene glycol (1,2-propanediol), and their systems composing of $6.25 \mathrm{~mL} 96.3 \% \mathrm{w} / \mathrm{w}$ ethanol, $2.5 \mathrm{~g}$ propylene glycol, and purified water up to $25 \mathrm{~mL}$ of total volume are used. Crushed crude propolis is soaked in an appropriate amount of solvent and left for maceration for seven days $[13,14]$. Manufactured extraction is filtered using paper filter.

\subsection{Determination of Total Phenolic Compounds Content.} Determination of total levels of phenolic compounds is based on colour-oxidation-reduction reaction using FolinCiocalteu reagent under alkaline conditions and performed at $765 \mathrm{~nm}$ wavelength using Unicam Helios $\alpha$ UV spectrophotometer (Unicam, Cambridge, UK). Total amounts of phenolic compounds are expressed as ferulic acid equivalent (FAE) $\mathrm{mg} / \mathrm{g}$.

Colour reaction: into $100 \mathrm{~mL}$ measurement flask $15 \mathrm{~mL}$ of purified water, $4 \mathrm{~mL}$ of Folin-Ciocalteu reagent depending on concentration and studied solution, and then $6 \mathrm{~mL}$ of $20 \%$ sodium bicarbonate are added. Diluted with purified water up to $100 \mathrm{~mL}$ measurement. The manufactured solution is stored for $2 \mathrm{~h}$ at room temperature for reaction to take place. Absorbtion is measured by reference solution using purified water $[15,16]$.

2.3. Determination of Microbiological Activity. The study is performed following the Ph. Eur. 01/2002, 2.6.12. Microbiological study is conducted under aseptic conditions. During microbiological study, MIC (minimum inhibitory concentration) - the highest dilution of preparation (the lowest concentration of preparation), which inhibits a certain growth of standard microorganism culture was determined. When the main solutions were prepared, dilutions were performed with $10 \mathrm{~mL}$ of Mueller-Hinton agar (MuellerHinton Agar, Becton, Dickinson and Company) to obtain working solutions in Mueller-Hinton agar, in which MIC effect of the studied preparations on the growth of standard microorganisms was determined. Then, every Petri dish containing dilutions and covered with Mueller-Hinton agar was inoculated with standard bacteria: Staphylococcus aureus, Klebsiella pneumoniae, Escherichia coli, Pseudomonas aeruginosa, Enterococcus faecalis, Proteus mirabilis, Bacillus cereus, Bacillus subtilis, and Candida albicans. Cultures were incubated for $24 \mathrm{~h}$ in thermostat at $37^{\circ} \mathrm{C}$ temperature, and then the growth of microorganisms in the zone of inoculation was evaluated.

\section{Results and Discussion}

3.1. Influence of Raw Material Concentration and Solvents Used on the Quality of Propolis Extracts. According to the data of the literature, different concentrations $(2.5 \%, 5 \%$, and $10 \%$ propolis) of water and water-free extracts of propolis were made $[13,14,17]$. Evaluation of the effect of solvent and concentration of propolis on amount of phenolic compounds was performed.

The data presented in Table 1 shows that when propolis concentration increases, the total amount of phenolic compounds in extracts increases. Statistically significant difference of means according to Student's $t$-test between $2.5 \%$ and $5 \%$ water extracts of propolis was determined, $P=0.032(P<0.05)$ as well as between $5 \%$ and $10 \%$ extracts, $P=0.03$. Statistically significant difference between studied ethanol extracts of propolis was determined $(P<0.05)$. When a $70 \%$ ethanol as solvent was used, the highest amount of phenolic compounds was released from $5 \%$ propolis extract, and the lowest amount from $10 \%$ propolis extract. More phenolic compounds were released from ethanolic extracts compared with water extracts of propolis. Statistical significant differences between studied propolis solutions in propylene glycol were determined. The highest amount of phenolic compounds was found in $10 \%$ propolis extract. When compared with water extracts, the amount of phenolic compounds was significantly higher but lower if compared with ethanolic extracts. According to the data [18, 19], to manufacture propolis extract, three-solvent system was used. The data shows that the lower extract concentrations, the higher amount of phenolic compounds is. The highest content of phenolic compounds was released from $2.5 \%$ propolis extract, and the lowest from $10 \%$. The difference between $2.5 \%$ and $5 \%$ propolis extracts, $P=0.06$ and between $5 \%$ and $10 \%, P=0.05$ was not statistically significant, and between $2.5 \%$ and $10 \%-P=0.006(P<0.05)$ - difference was statistically significant. The results of the studies showed that the amount of phenolic compounds in propolis extracts depended not only on raw material concentration but also on solvent used in extraction process. Moreover, the data of the studies illustrates that during extraction process a big marginal layer develops and diffusion does not occur, suggesting that technological factors improving diffusion should be introduced [17].

3.2. Effect of Stirring on the Quality of Propolis Extracts. In order to improve the extraction of active substances, extracts with three-solvent system and propylene glycol propolis extracts were stirred with magnetic stirring. Stirring has been performed for $3 \mathrm{~h}$; samples for the analysis of phenolic compounds were taken after $1 \mathrm{~h}$, after $2 \mathrm{~h}$, and after $3 \mathrm{~h}$ of stirring, respectively. 
TABLE 1: Total amount of phenolic compounds expressed as FAE $\mathrm{mg} / \mathrm{g}$ in propolis extracts. Data presented as mean $\pm \mathrm{SD}, n=3$.

\begin{tabular}{ccccc}
\hline & & \multicolumn{3}{c}{ Total amount of phenolic compounds (mg/g) } \\
Solvents & & $2.5 \%$ & $5 \%$ & $10 \%$ \\
\hline & Water & $14.4 \pm 0.22$ & $17.0 \pm 1.12$ & $19.6 \pm 0.93$ \\
Propolis extracts & Ethanol & $167.5 \pm 2.78$ & $175.6 \pm 1.89$ & $115.4 \pm 2.20$ \\
& Propylene glycol & $97.9 \pm 1.23$ & $118.6 \pm 1.78$ & $17.4 \pm 2.54$ \\
& Three-solvent system & $85.4 \pm 1.65$ & $82.5 \pm 1.36$ & $73.7 \pm 1.32$ \\
\hline
\end{tabular}

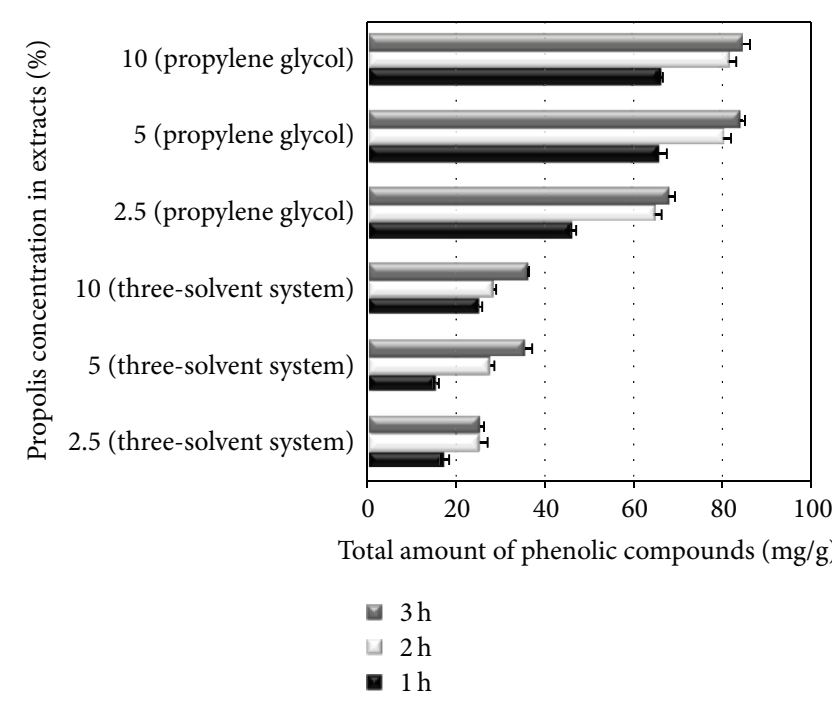

FIGURE 1: Effect of stirring ontotal amount of phenolic compounds.

The results of the study showed that stirring had an effect on the release of phenolic compounds from extracted raw material-after $1 \mathrm{~h}$ of stirring the highest amount of phenolic compounds was released from $2.5 \%$ propolis extract, and the lowest from $10 \%$, and after $3 \mathrm{~h}$ the lowest amount of phenolic compounds was released from $2.5 \%$ propolis extract, but the highest amount from $10 \%$ propolis extract. However, a comparison of the data after two hours of stirring did not determine significant higher amounts of phenolic compounds. Differences between the total amount of phenolic compounds in the all studied propolis propylene glycol extracts and $2.5 \%$ propolis in three-solvent system stirred for 2 and $3 \mathrm{~h}$ were not statistically significant $(P>0.05)$. Figure 1 shows an increase of phenolic compounds during stirring. It suggests that the optimal time to stir is $2 \mathrm{~h}$. Also was established that the most suitable extraction method for propolis solution in solvent mixture is maceration. The higher amount of phenolic compounds was in propolis solution in three-solvent system produced using the method of maceration than in propolis solution prepared using stirring.

3.3. Influence of Temperature and Stirring on Propolis Extracts. To evaluate the influence of temperature, $5 \%$ propolis solutions in propylene glycol were used. Stirring was performed

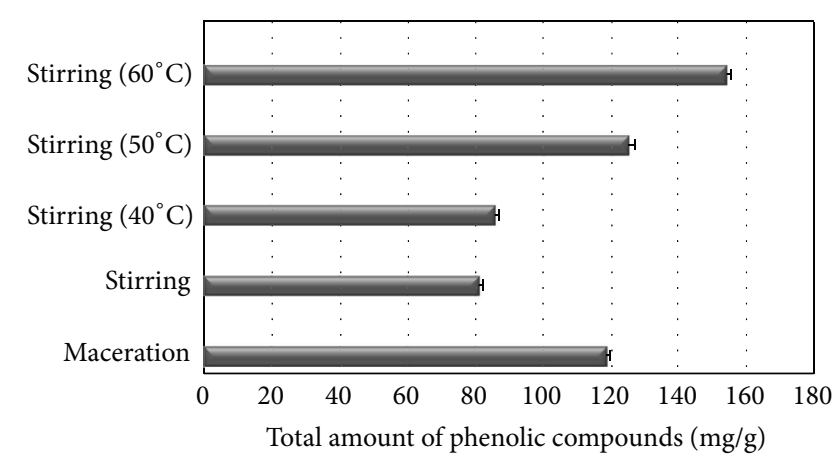

FIGURE 2: Influence of temperature on total amount of phenolic compounds in $5 \%$ propolis propylene glycol extracts.

at different temperatures $\left(40,50\right.$, and $\left.60^{\circ} \mathrm{C}\right)$, time of stirring$2 \mathrm{~h}$. For the analysis, $5 \%$ propolis solutions in propylene glycol were used.

The results showed that the lowest amounts of phenolic compounds were released when solutions were stirred for $2 \mathrm{~h}$ at $40^{\circ} \mathrm{C}$ temperature $-85.6 \pm 0.56$, at $50^{\circ} \mathrm{C}$ temperature$125.2 \pm 0.71(P<0.05$, Student's $t$-test $)$, and the highest content was observed when stirred for $2 \mathrm{~h}$ at $60^{\circ} \mathrm{C}$ temperature$153.8 \pm 0.94(P<0.05$, Student's $t$-test $)$. It suggests that an increase of temperature has an influence on the amount of phenolic compounds. When comparing extracts obtained at different temperature, significant differences between the amounts of active substances were determined. The most effective release was occurring when $60^{\circ} \mathrm{C}$ was maintained. Investigation showed that maceration method is appropriate for preparing the propolis propylene glycol extracts. However, stirring at $50^{\circ} \mathrm{C}$ and higher temperature were more effective than maceration $(P<0.05$, Student's $t$-test) (Figure 2).

3.4. Determination of Microbiological Activity of Propolis Solutions. The results of the study showed that water extracted propolis and propolis solution in three-solvent system (water-ethanol-propylene glycol) were not effective against the studied strains of microorganisms. Ethanol 2.5\% propolis extracts were more effective against the studied microorganisms compared with other investigated extracts. The result showed that the growth of Klebsiella pneumoniae was most resistant to the effect of propolis ethanol extract and the MIC of phenolic compounds was $0.5 \mu \mathrm{g} / \mathrm{mL}$. Gramnegative bacteria Escherichia coli, Pseudomonas aeruginosa, 


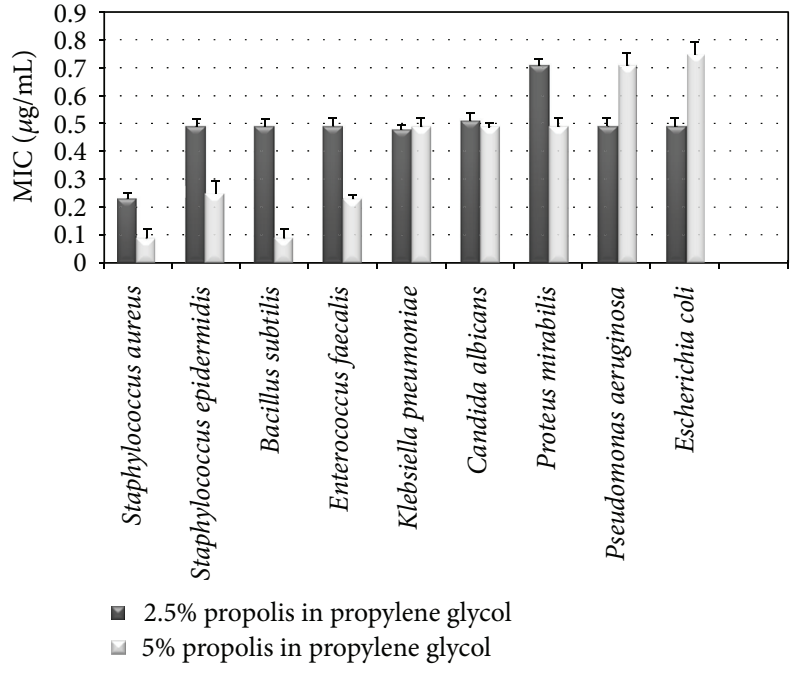

FIGURE 3: Microbiological activity of propolis phenolic compounds in propylene glycol solutions.

and Proteus mirabilis were more sensitive, the determined MIC $0.28 \mu \mathrm{g} / \mathrm{mL}$, compared to gram-positive bacteria. The MIC for the growth of Staphylococcus aureus was $0.17 \mu \mathrm{g} / \mathrm{mL}$, and for Enterococcus faecalis- $0.2 \mu \mathrm{g} / \mathrm{mL}$. The most sensitive microorganisms to be studied ethanol extracts were Candida albicans and Bacillus cereus, Bacillus subtilis-the MIC was $0.06 \mu \mathrm{g} / \mathrm{mL}$. Propolis solutions in propylene glycol showed the greatest effect against Staphylococcus aureus, and Bacillus subtilis (Figure 3).

These solutions were also active against the other studied microorganisms (Figure 3). The studies of antimicrobial activity of propolis extracts showed that solvents had the influence on microbiological activity of propolis extractswater extracted propolis solutions did not inhibit the growth of the studied microorganisms. The technology of this solution and evaluation of composition require additional researches.

\section{Conclusions}

Crude propolis concentration has an influence on the amounts of phenolic compounds in propolis extracts when water, ethanol, or propylene glycol are used in the process of extraction. The highest content of phenolic compounds was determined in solutions containing $10 \%$ propolis extracts, and the lowest amounts-2.5\% propolis extracts. The results revealed that water used in the process of extraction extracts the lowest amount of phenolic compounds from crude propolis, ethanol-the highest amount, and propylene glycol ranks the middle position.

It is determined that technological parameters (stirring, temperature) contribute to the content of phenolic compounds when propylene glycol as solvent was used. The highest amounts of phenolic compounds was determined when temperature was $60^{\circ} \mathrm{C}$, and stirring time $-2 \mathrm{~h}$.

The studies showed that higher content of active substances is obtained when ethanol was used. However, the data also demonstrated that both solvents used were suitable for crude propolis extraction because propylene glycol extracted propolis solutions had antimicrobial activity. Since propylene glycol is nonvolatile and contains no water, it may be widely used as solvent in manufacturing of propolis solutions.

\section{Conflict of Interests}

There is no conflict of interests to declare.

\section{References}

[1] M. C. Marcucci, "Propolis: chemical composition, biological properties and therapeutic activity," Apidologie, vol. 26, no. 2, pp. 83-99, 1995.

[2] K. Sorkum, S. Bozcuk, A. N. Gömürgen, and F. Telkin, "An inhibitory effect of propolis on germination and cell division in the root tips of seedlings," in Bee Produkts. Properties, Applications, and Apiterapy, Plenum Press, New York, NY, USA, 1997.

[3] B. Tosi, A. Donini, C. Romagnoli, and A. Bruni, "Antimicrobial activity of some commercial extracts of propolis prepared with different solvents," Phytotherapy Research, vol. 10, pp. 335-336, 1996.

[4] A. Uzel, K. Sorkun, Ö. Önçağ, D. Çoǧulu, Ö. Gençay, and B. Salih, "Chemical compositions and antimicrobial activities of four different Anatolian propolis samples," Microbiological Research, vol. 160, no. 2, pp. 189-195, 2005.

[5] A. H. Banskota, Y. Tezuka, and S. Kadota, "Recent progress in pharmacological research of propolis," Phytotherapy Research, vol. 15, no. 7, pp. 561-571, 2001.

[6] I. Kosalec, S. Pepeljnjak, M. Bakmaz, and S. Vladimir-Knežević, "Flavonoid analysis and antimicrobial activity of commercially available propolis products," Acta Pharmaceutica, vol. 55, no. 4, pp. 423-430, 2005.

[7] A. Kujumgiev, I. Tsvetkova, Y. Serkedjieva, V. Bankova, R. Christov, and S. Popov, "Antibacterial, antifungal and antiviral activity of propolis of different geographic origin," Journal of Ethnopharmacology, vol. 64, no. 3, pp. 235-240, 1999.

[8] V. Bankova, "Recent trends and important developments in propolis research," Evidence-Based Complementary and Alternative Medicine, vol. 2, no. 1, pp. 29-32, 2005.

[9] A. G. Hegazia, F. El Hadyb, and F. Allah, "Chemical composition and antimicrobial activity of European propolis," Zeitschrift für Naturforschung, vol. 55, pp. 70-75, 2000.

[10] S. Silici and S. Kutluca, "Chemical composition and antibacterial activity of propolis collected by three different races of honeybees in the same region," Journal of Ethnopharmacology, vol. 99, no. 1, pp. 69-73, 2005.

[11] G. Čerkašinas, A. Gendrolis, A. Pavilonis, and R. Klimas, "Lietuvoje surinkto propolio antimikrobinis aktyvumas. (Antimicrobial activity of propolis collected in Lithuania)," Medicina, vol. 33, pp. 1193-1198, 1997.

[12] P. G. Pietta, C. Gardana, and A. M. Pietta, "Analytical methods for quality control of propolis," Fitoterapia, vol. 73, supplement 1, pp. S7-S20, 2002.

[13] I. B. S. Cunha, A. C. H. F. Sawaya, F. M. Caetano et al., "Factors that influence the yield and composition of Brazilian propolis extracts," Journal of the Brazilian Chemical Society, vol. 15, no. 6, pp. 964-970, 2004. 
[14] B. Trusheva, D. Trunkova, and V. Bankova, "Different extraction methods of biologically active components from propolis; a preliminary study," Chemistry Central Journal, vol. 1, article 13, 2007.

[15] M. G. Miguel, S. Nunes, S. A. Dandlen, A. M. Cavaco, and M. D. Antunes, "Phenols and antioxidant activity of hydro-alcoholic extracts of propolis from Algarve, South of Portugal," Food and Chemical Toxicology, vol. 48, no. 12, pp. 3418-3423, 2010.

[16] M. Popova, V. Bankova, D. Butovska et al., "Validated methods for the quantification of biologically active constituents of poplar-type propolis," Phytochemical Analysis, vol. 15, no. 4, pp. 235-340, 2004.

[17] R. C. Rowe, P. J. Sheskey, and M. E. Quinn, Handbook of Pharmaceutical Excipients, Pharmaceutical Press, London, UK, 2009.

[18] F. Marquele-Oliveira, Y. M. Fonseca, O. de Freitas, and M. J. V. Fonseca, "Development of topical functionalized formulations added with propolis extract: stability, cutaneous absorption and in vivo studies," International Journal of Pharmaceutics, vol. 342, no. 1-2, pp. 40-48, 2007.

[19] F. D. Marquele, A. R. M. Oliveira, P. S. Bonato, M. G. Lara, and M. J. V. Fonseca, "Propolis extract release evaluation from topical formulations by chemiluminescence and HPLC," Journal of Pharmaceutical and Biomedical Analysis, vol. 41, no. 2, pp. 461-468, 2006. 


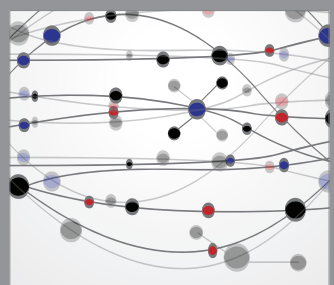

The Scientific World Journal
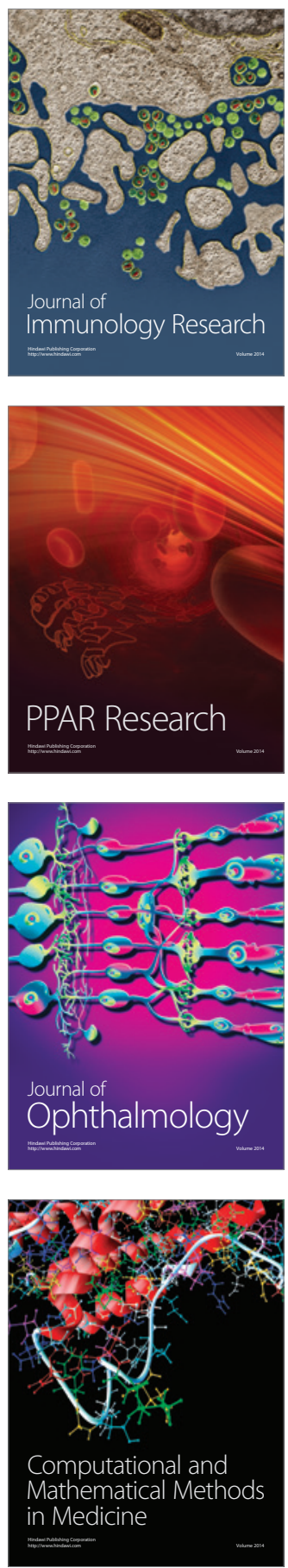

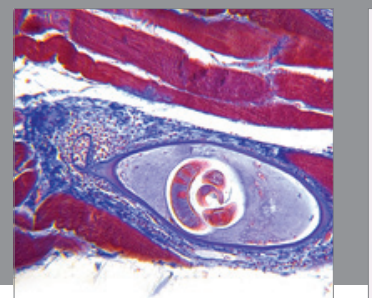

Gastroenterology

Research and Practice
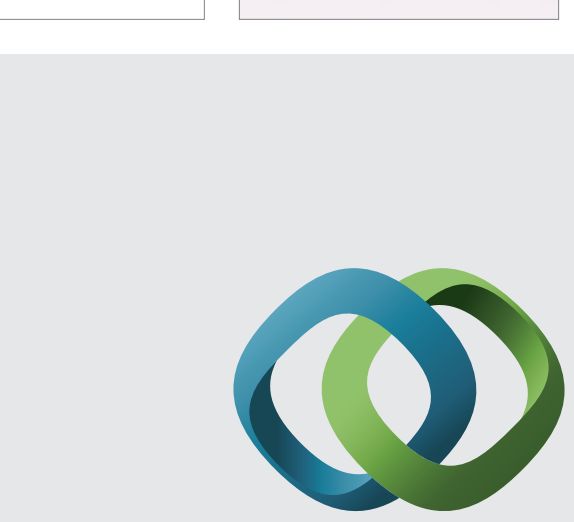

\section{Hindawi}

Submit your manuscripts at

http://www.hindawi.com
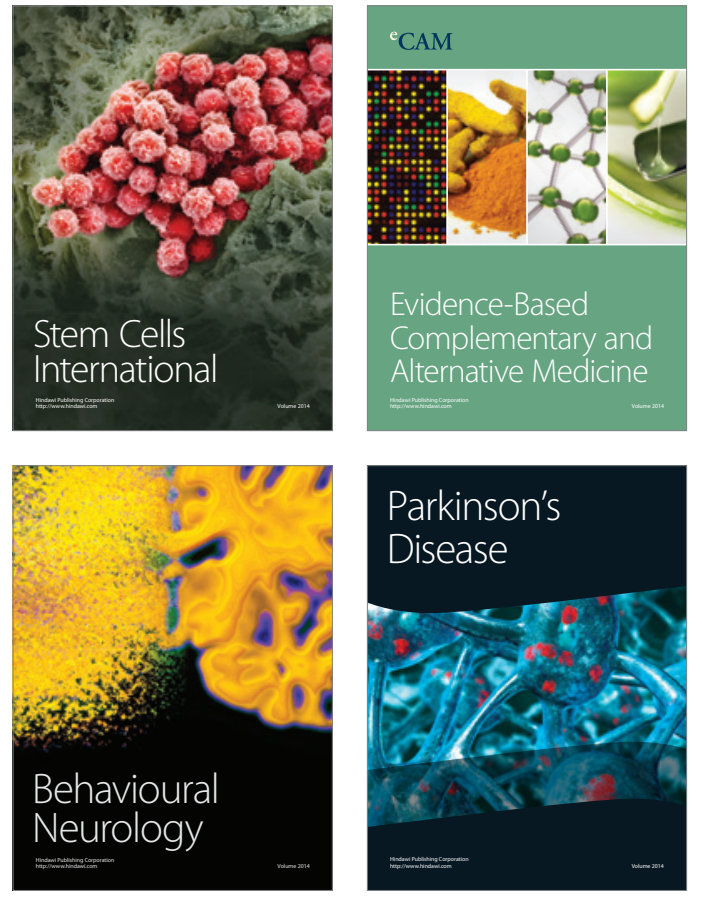
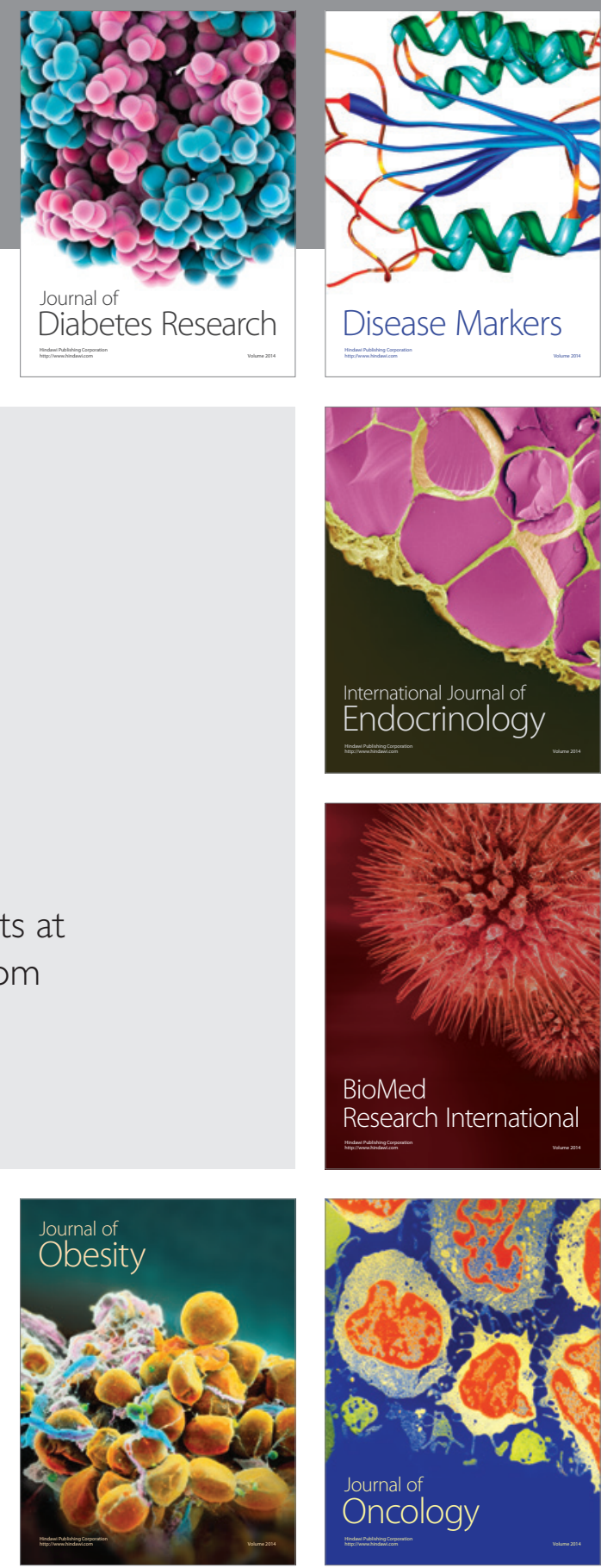

Disease Markers
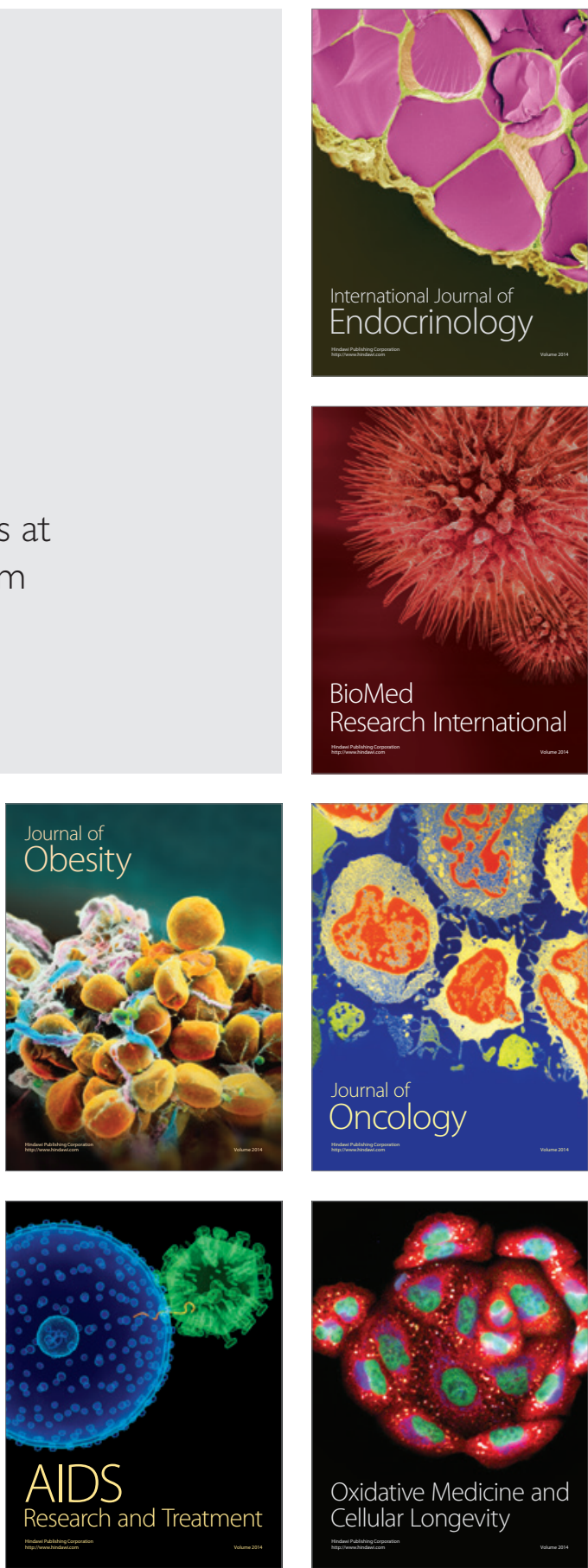